"This is an Accepted Manuscript of an article published by Taylor \& Francis in Studies in European Cinema on 01/03/13, available online:

https://www.ingentaconnect.com/content/routledg/sec/2013/00000010/00000001/art00004 


\title{
The French Female Butterfly Collector: Hadžihalilović, Denis, de Van and the cinéma du corps
}

\section{Davina Quinlivan (King’s College, London)}

\begin{abstract}
This paper develops an examination of the films of Lucile Hadžihalilović, Claire Denis and Marina de Van in the context of the French École du corps (school of 'body cinema') and the on-going theorization of the French cinéma du corps movement. I argue that Denis, Hadžihalilović and de Van collectively, and abstractly, evoke the figure of the 'female butterfly collector': each filmmaker is seen to preserve and embalm their filmed objects and artefacts via experimentation with colour and form, in cinematographic terms, and through themes of mortality, metamorphosis and retreat in the diegesis of their films. While attention will be paid to the specificity of Hadžihalilović, Denis and de Van's work, this paper's conceptual engagement with the notion of butterfly collecting, as artistic and scientific endeavour, also offers new insights into the overall appeal of the French 'cinema of sensation' (Beugnet, 2008). The paper's elaboration on Hadžihalilović's invocation of the female butterfly collector in Innocence (2004), and its implications for spectatorship and the filming of the female body, leads to a re-evaluation of the corporeal cinema of Denis and de Van and their contribution to the French cinéma du corps.
\end{abstract}

\section{Contributors Details}

Davina Quinlivan is a lecturer in Film Studies at Kingston University. She holds a PhD in Film Studies from King's College, London. Her first book is a study of embodiment in the films of Atom Egoyan, Lars von Trier and David Cronenberg with the philosophy of Luce 
Irigaray, entitled The Place of Breath in Cinema (Edinburgh University Press 2012). Her article 'Material Hauntings: the Kinaesthesia of Sound in Innocence' received the 2009 Studies in French Cinema Best PhD article prize.

Contact details: davina.quinlivan@kingston.ac.uk

\section{Keywords}

Stillness

Framing

Mortality

Sensation

Modernism

Metamorphosis

A key sequence in Innocence (Hadžihalilović, 2004) offers a pictorial image of a female butterfly collector. Mademoiselle Edith, a school mistress, sits in a darkened room, clasping a pair of tweezers and a craft knife. Edith works with what appears to resemble a dead cabbage butterfly, arranging its wings and gently coaxing apart its folded anatomy. Alongside the movement of her hands, a butterfly collector's kit is set out against the ochre grain of a wooden desk; we glimpse an exhibit case, glass bottles containing ethyl acetate (poison), insect pins and tweezers. The camera hovers just above Edith's shoulders, resting at the edge of her arm and catching the slight curve of her chin; the silver tweezers contrast her pink fingernails and her pale skin as the metallic pincers move across the desk and search for a tiny object flecked with light. In the upper part of the image, a sharp corner of a display box points towards the angle of Edith’s framed, lower arm and we see scarlet backing paper 
beneath a collection of already encased butterflies. Edith shakes out a folded envelope and empties its contents on to her desk. We see a small thing, papery like the envelope. While the whiteness of the butterfly throws into relief the flushed, yet translucent skin of the human hands on the desk beside it, concentrating the viewer's attention on the aesthetic of the film, what is made even more apparent in this scene is the invisible presence of the female director whose incisive actions double the delicate, yet also rigorous work Edith performs on her assembled collection of butterflies. It would seem then, that the image of Edith with her scientific tools is also Hadžihalilović’s self-portrait, in which she identifies herself with the female butterfly collector and indeed the role of Edith as schoolmistress.

In interview, Hadžihalilović has admitted she never went to boarding school but longed to experience life within such a place. ${ }^{1}$ Yet, it is Edith and not one of the schoolgirls that tends to emerge as the French female director's double, a guardian of a preserved, and adored self-contained world. As we shall see, the work of Claire Denis and Marina de Van also suggests an aesthetic practice configured through the manipulation of the medium, interrogating film's embalming, plastic qualities and their differing responses to the body as an entity in-flux or, rather, in metamorphosis, like the butterflies of Hadžihalilović's allegory.

Innocence, Hadzililovic's adapatation of Frank Wedekind's novella Mine-Haha or the Corporeal Education of Young Girls, takes place within the expansive, yet secure walls of a boarding school for girls. Like the wolves in Angela Carter's The Company of Wolves (Jordan, 1984) or the bees in The Spirit of the Beehive/El espíritu de la colmena (Erice, 1973), the natural world symbolizes the turbulent, inner emotional and outer, material volatility of female embodiment. For Hadžihalilović, butterflies are twinned, doubled, with the child subjects of her film. Indeed, while assembling her butterfly collection, Edith discusses with another teacher the fate of one of the girls once she leaves the school, and admits that 'outside may not be what she expects (...) if she is disappointed she will suffer'. 
There are multiple layers of doubling within this scene; it closes in upon itself . Thus, the fate of the schoolgirl Edith refers to seems to be irrevocably bound up with the fate of the butterfly, clasped within her tweezers. Hadžihalilović perceives her young, female subjects as butterflies re-animated, resurrected through her lively use of tableaux vivants, but her explanation of her aesthetic choices also uncovers a strong identification with the role of the butterfly collector whose passion and pleasure lies in the netting and pinning of her subjects, and their cinematographic embalming. This article argues that the analogy of filmmaker as butterfly collector is also relevant to a wider analysis of French female filmmakers at the centre of the cinéma du corps movement in France. Hadžihalilović is seen to adopt a mode of cinematographic sensuality that is comparable with the films of Denis and de Van, in particular, and their collective envisioning of the female body, as a site of fascination, metamorphosis and visual disturbance. Beginning with the figuration of the female butterfly collector in Innocence, questions are then raised about the representation of metamorphosis and its implications for the analysis of viewing relations, silence and light (especially electricity, sunlight and artificial light) in Innocence, Trouble Every Day (Denis, 2001), and In My Skin/Dans ma peau (de Van, 2003).

Butterfly motifs, including images of chrysalises and pupae, are scattered throughout Innocence and they anchor the film's sensorial pleasures. In her article 'Waking Life: Vivian Sobchack on the Experience of Innocence', Sobchack claims that the images of Innocence are 'rich with meaning but only really graspable in their richness not through intellect but through a form of “carnal thought' (Sobchack 2005:49). For Sobchack, the vistas and landscapes filmed in Innocence are especially key to its embodied film experience. However, the diegetic images of butterflies, and their embedding in the film itself, are also particularly involved in the film's sensate pleasures. Furthermore, cast in the role of female filmmaker/butterfly collector, Hadžihalilović shows us the literal and symbolic frames of 
experience which cut across the parameters of both the diegesis and the aesthetic invitation to sensation.

Sobchack's reflection on Innocence, in particular, reinforces its value within the current tradition of the French cinéma du corps movement, a form of filmmaking whose focus on an aesthetic of sensation 'reaffirms the practice and experience of cinema as a mode of affective thinking' (Beugnet 2008: 175). For Martine Beugnet, contemporary French filmmakers increasingly ‘betray a characteristic sensibility to and awareness of cinema’s sensuous impact and transgressive nature’ (Beugnet 2008, 174). In this context, Beugnet draws attention to a number of films which tend to invariably deepen our understanding of the medium’s material qualities; Beugnet’s list consists of; ‘Baise-moi (Despentes and TrinhThi, 2000); Beau Travail (Good Work, Denis, 1999); La Captive (The Prisoner, Akerman, 2000); Dans ma peau (In My Skin, de Van, 2003); Demonlover (Assayas, 2002); L'Humanité (Humanity, Dumont, 1999); L'Intrus (The Intruder, Denis, 2005);; Romance (Breillat, 2000);; Trouble Every Day (Claire Denis, 2001); Twentynine Palms (Dumont, 2003); Vendredi soir (Friday Night, Denis, 2002); La Vie nouvelle (A New Life, Grandrieux, 2002); Wild Side (Lifshitz, 2004); Zidane, un portrait du XXIème siècle (Zidane: A $21^{\text {st }}$ Century Portrait, Gordon and Parreno, 2006)' (Beugnet, 2008: 174-5). While Beugnet's thought crystallizes current concerns with affective modes of film viewing especially informed by the poststructuralist philosophy of Gilles Deleuze, the transgressive dimensions of the cinéma du corps are inherently brutalist and uncompromising, according to Tim Palmer (Palmer 2009: 317). In a wider context, a recent publication entitled The New Extremism in Cinema: From France to Europe (Horeck and Kendall 2011) tends to examine the 'cinema of the body' movement beyond its French specificity, highlighting issues of censorship, revolt and unpleasure in the work of European directors including Lars von Trier, Lukas Moodysson and Michael Haneke. If Innocence is to be treated as an example of the French cinéma du 
corps movement, then, it refocuses questions of transgression towards the notion of metamorphosis, a term which tends to be more in line with Beugnet's attention to the affirmative gestures at the heart of the movement rather than the perspective adopted by Palmer, which privileges brutality. In these terms, Innocence is especially comparable with the films of Denis and de Van and their collective, textural evocation of the female body as a site of metamorphosis.

In addition to the stylistic and thematic evocation of metamorphosis that is felt in the work of Hadžihalilović, Denis and de Van, their films also share the same cultural specificity. For Palmer, Innocence ‘exemplifies a pivotal segment of France’s contemporary cinema, as a conceptually bold and widely travelled debut feature, made by a female graduate of a French film school' (Palmer 2009: 319). De Van and Denis's work is similarly informed by the same intellectual and cultural heritage, since they are both former graduates of the prestigious French film school La Femis (formerly L'Institut des hautes études cinématographiques); they are not only women filmmakers working in France, but graduates of a system historically and politically involved in the production of French cultural values (La Femis is supervised by the French Ministry of Culture). Palmer usefully elaborates on the feminine style of filmmaking privileged in the cinéma du corps, precisely focusing on Innocence as an example of a wider trend in which larger-scale women's cinema in France has contributed to the resurgence of French cinema (Palmer 2009: 317). Furthermore, Palmer views Innocence as a key example of a particular kind of filmmaking characterised by its stylistic experimentation, 'textual polyvalence, and cine-literacy informed by a sophisticated pedagogy of French film schools’ (Palmer 2009: 317). Yet, beyond their shared schooling and general compatriotism, Hadžihalilović, Denis and de Van can be more precisely viewed as a collective of filmmakers, from two different generations, whose interest lies entirely in forging intimate and uncompromising cinematic encounters transformed by the evident, and 
preciously envisaged, matter of their subjects. They are like butterfly collectors, sweeping their conceptual frames and nets over their subjects in order to create new worlds and preserved moments of existence.

\section{The Cinematic Aesthetics of 'Butterfly Collecting' and the Cinéma du corps}

Before Innocence, Hadžihalilović was best known for her collaborative work with her husband Gaspar Noé, editing both Seul contre tous (I Stand Alone, 1998) and Carne (Meat, 1991). Recently,

Hadžihalilović has collaborated again with Noé as co-writer on Enter the Void (2010). Much criticism of Innocence has drawn attention to Hadžihalilović’s cinematic formulation of various tableaux vivants featuring the subjects of her film at play. Hadžihalilović and her cinematographer Benoît Debie (best known for his collaboration with Noé on the 2002 film Irréversible and, more recently, his work on Noé’s Enter the Void) frame groups of girls at play as hyper-real tableaux vivants, employing CinemaScope and photographing them using Super-16 which was then digitally enhanced to deepen the colour saturation of the film stock. For the film critic Jonathan Romney, the tableaux vivants are 'vividly real, yet abstract' (Romney 2005: 35) highlighting the ways in which the images of the children appear both strange and familiar, real and unreal, qualities that resonate with the pleasures of butterfly collecting, their exoticism and exquisite, anatomical perfection. ${ }^{2}$

In interview, Hadžihalilović comments on the strategic use of tableaux vivants in her debut feature, describing their role as a kind of visual tactic which involves framing her child subjects as though she were 'pinning butterflies in a box'. ${ }^{3}$ Hadžihalilović's comments are intriguing given the diegetic presence of butterflies in Innocence and their intertwined involvement in the film's evocation of adolescent, female sexuality and its particular staging 
as metamorphosis. Yet, it is also Hadžihalilović's specific style of filmmaking which elicits acute correlations between the art of butterfly collecting, the filmmaking processes she adopts and the questions of being and mortality at the centre of the viewing experience of Innocence. In view of Hadžihalilović’s statement regarding her likening of the process of filming her child subjects to 'pinning butterflies in a box', the role of containment, or rather the role of the frame, seems most appropriate to my concerns with the filmic corollaries of butterfly collecting. Containment of subjects, of spaces, and of the viewer's experiences, localised and enclosed, that is, containment of an invisible world of the living that is microscopically pieced together and woven into the fabric of the film.

My engagement with the notion of the filmmaker as butterfly collector not only serves to elaborate further on the position of the female filmmaker, but also raises new questions about the mediating properties of the screen which, like the butterfly collector's glass display cabinets, mediates our experience of the framed subjects. Indeed, like many other forms of collecting, butterfly collecting involves to some extent, a kind of scopophilia associated with mastery, an exercise of power and visual pleasure. The presence of the frame, of stillness and silence, the screen of glass and, indeed, the container, is important here, but their filmic corollaries - the formal use of framing and the viewer's experience of the screen, in Innocence, suggests that Hadžihalilović's butterfly collecting might be more preservatory and restorative than scopophilic, while still operating within terms that resonate with the practice of butterfly collecting. For example, during a scene in which two of the school girls journey through the wood at dusk, Hadžihalilović films the girls with their backs facing us as they walk up and out of the frame; this sequence denies viewers access to the faces and thus to intimate knowledge conveyed by facial expressions or gestures - their bodies, too, like their faces, become unknowable, literally enacting a slow and steady move away from us and escaping our grasp, 
preserving their subjectivity. In this, the off-screen space of the frame comes to represent the mysterious realm of innocence that the girls inhabit.

On a diegetic level, the film opens with the sound of a train whirring over train tracks, then a series of passages and tunnels, implied only through static images of subterranean caverns and wells accompanied by live sounds of water gushing, dripping and damp walls. This sequence is a framing device: the butterfly collector Hadžihalilović slips a frame over her film. Further in line with the metaphor of the frame, these opening moments signal a containment of the viewer's sense of hearing, reining it in, and sharpening their aural perception. Here, as the film begins, the viewer is the boxed butterfly. Yet, while the inside of a butterfly collector's box might be silent, viewers experience the reverse, as if the outside world were not alive enough, deadly silent until they make contact with the film's opening images. While tunnels and the deep, rumbling sound of traversing across uneven train tracks suggests an abstract entering into Hadžihalilović’s contained world, the coffin carrying the girl (Iris) whose journeying marks the start of the film is also a diegetic container, a symbol that plays with our expectations and foreknowledge of the boundaries between life and death: the containment that is suggested through the image of the coffin is thus not suggestive of the end of life, like the pinned butterflies in the glass boxes, but rather, conversely, bears comparison with the butterfly pupae Edith shows the girls_-containment as a means of preserving life and renewing it.

Similarly, the cinematographic style and thematic qualities of Denis’s Trouble Every Day and de Van's In My Skin, in particular, reflect concerns with the preservation of selfhood and the body as a site of metamorphosis. Like the butterfly-schoolgirls in Innocence, the protagonists of Denis and de Van's films are adult women caught up in the 'nets' of the French filmmakers, but their bodies are more explicitly, and viscerally, implicated in the process of demarcating a kind of metamorphosis in action. This metamorphosis extends to the 
viewing relations of Trouble Every Day and In My Skin, and each film's formal rendering of physical destabilization and vulnerability. While Hadžihalilović might 'pin’ her child subjects into the frames of her film and the lush, diegetic environs she situates her film within, de Van and Denis adopt an aesthetic of stillness and silence in which their female protagonists are posited as inherent sites of fascination.

\section{A 'Pupae’ Visuality: Metamorphosis, Hadžihalilović, de Van and Denis}

In Vers Mathilde(Towards Mathilde), Denis’ 2005 documentary about the French choreographer Mathilde Monnier, the dancer reflects on the nature of memory and its inscription on the body:

Whenever you make an incursion into a space, that space is altered. I like this idea of leaving a scratch, because that space is altered by that scratch after. It's like a piece of paper that has a mark on it and is no longer blank; there's something dirtying it. The scratch idea has other aspects: the energy you put into it, the weight, the breathing - it’s infinite. In other words, the memory leaves a mark ... and this mark leaves a mark on the body.

(Mathilde Monnier in Claire Denis’ Vers Mathilde, quoted in Martin, 2009)

Like the cinematographic manipulation, or 'incisions' ${ }^{4}$ Hadžihalilović makes in the fabric of Innocence in order to 'pin’ her subjects into her colour-saturated world, Monnier’s comments are comparable with film aesthetics and, in particular, the affective dimensions of the cinéma du corps in which 'we have to unlearn before we can learn to see and feel again' (Beugnet, 2008: 184). This dimension of the cinéma du corps which requires a new sensitivity to the materiality of vision and, by extension, the reversibility of subjective and objective modes of 
experience, can be characterised in terms relating precisely to the concept of metamorphosis. Indeed, what Monnier elegantly describes is a kind of bodily openness, and sensitivity, to change and this gesture is expressed frequently in the work of Denis, as well as de Van and Hadžihalilović. For Adrian Martin, it is the questioning of desire, its purpose, its conception, which most informs Denis’ cinéma du corps and her protagonists’ openness to the unknown, to the re-organisation of matter. Such 'openness' is archaic, according to Martin.

Commenting on the brutality of Denis's Trouble Every Day, he describes the film as an exploration of an 'intimate, animal drive' (Martin 2009), but far from being ossifying, this drive is energising, restoring, spilling over into the textural qualities of the film itself.

Denis’ vampiric Trouble Every Day examines a group of young people affected by a scientific experiment which encourages bloodlust, in equal measures capable of mutilation and tender seduction. In one of the film's most striking scenes, Beatrice Dalle’s character Coré is seen hailing a red truck, its tarpaulin taut and prescient of the many images of skin throughout Trouble Every Day, shot in gauzy traffic-light reds. However, as the violent death of the truck driver implies at the end of the sequence, we come to know skin in two ways: as mottled, scratched, punctured, and as unbroken, smooth and wet with blood that has been the result of contact with another's wounded body. The image is also another kind of skin, according to the thought of Jean-Luc Nancy, 'it makes an image of the skin: it doesn't just show skin, but slips it into the plane of the image, it tends to confuse the screen with the skin, it films skin where filming would mean following, filtering, freezing' (Nancy 2008: 6). Thus, like the butterfly bursting from its cocoon in Innocence, transgression occurs as an inward and outward movement in which part of the self is reconstituted in order to configure something new, or as Nancy puts it, 'covering oneself on the outside with the raw, warm inside that the skin suggests and envelops' (Nancy 2008: 7). While Martin argues that 'Denis' films are switched on to the sensual chemistry or alchemy of two bodies in proximity', such 
an alchemy also exists between viewers and the images of Denis’ films, and their proximal 'convergence' is thus an intersubjective metamorphosis of vision.

While the sensory aesthetics of Innocence and Trouble Every Day invite their viewers to participate in the metamorphosis of their subjects, In My Skin's formal use of sound enables a different kind of diegetic and spectatorial metamorphosis to take place. In My Skin is ostensibly a film about a young woman (played by de Van) equally trapped and enthralled by an obsession. Esther falls over at a party one night and injures her upper leg, prompting her to fixate on the wound and develop an objectified perspective on her own body, sometimes imagining body parts as disconnected objects she must control and even stab into submission. De Van avoids comparisons with Cronenbergian body-horror, focusing on what Palmer has called 'a kind of tenderness and curiosity...a softness and sweetness in the way Esther touches her own skin and blood' (Palmer 2006: 178). Like the images of butterfly pupae in Innocence, Esther undergoes a metamorphosis, retreating into herself and opening her body (literally) to an unknown, but much longed for renewal and affirmation of existence. This is corroborated by the visuality of the film which, as Carrie Tarr has observed, adopts a 'poetic aesthetic' (Tarr 2006: 86). There are similarities between Trouble Every Day and In My Skin, as Palmer has also noted (Palmer 2006), but the main difference is that Esther perceives herself as her own objectified other and hers is the only skin frequently filmed in close-up. Indeed, in one scene, Esther starts to make a catalogue of her experiences, beginning with a sample of her own translucent skin, protected between two slides of glass. Later, Esther takes polaroids of herself, collecting and re-affirming, enhancing the visual pleasure she gains from looking at her body as pure, bleeding matter. Like Edith in Innocence, there is an entomologist's repose adopted by Esther, a role artificially constructed through the employment of props such as the butterfly collector's tweezers and Esther's 
polaroid camera. However, as I have suggested already of Innocence, the entomologist's role is doubled by the filmmaker behind the lens of the camera.

Like the stillness and silence of the butterflies captured in Innocence, de Van's use of sound design, created by Jéröme Aghion, Jéröme Wiciak and Cyril Holtz, captures a different sense of mortality and articulation of intimacy. Frequently, viewers are invited to listen to de Van’s sharp gasps, breaths and sighs as she deepens her wounds, mutilating her skin and pulling at clothing fibres soaked in blood. The first time Esther self-mutilates, the camera moves up and away from de Van’s wounded leg, focusing on her face. In near darkness, we hear nothing, for a moment, as if Esther is holding her breath, then, several exhalations. ${ }^{5}$ Thus, de Van's fostering of intimacy is predicated on sound rather than the viewer's proximity to her body, or gratifying close-ups of her wounded limb. De Van constructs a hermetically sealed world, like Innocence and its framing of existence; these worlds permit their subjects to metamorphose in ways which invariably designate off-screen spaces as the site par excellence of transformation, spaces which also call forth the imagination of the viewer.

\section{Concluding thoughts: Light, Metamorphosis}

Just as light enters the layers of a butterfly’s chrysalis, light as its cinematographic manipulation is important to the visuality of metamorphosis in Innocence, In My Skin and Trouble Every Day. If the act of metamorphosis can described as something which occurs off-screen, then light tends to be involved in the visible and material inscription of the unknown or one might call the 'aura' of transformation. While I want to identify the role of light in the filmic diegesis of the three films analysed in this paper, the viewer's experience of 
light can also be understood in sensuous terms, building on the affective model of film experience privileged by Beugnet.

While Hadžihalilović identifies with the role of the butterfly collector, her filmic concern with the sound and visuality of electricity, light and illumination emphasizes the medium she employs, its debt to scientific experimentation and the modernity of the film itself. Light shimmers from above wooded canopies in Innocence, but it is also artificially suggested: moon-shaped electric lamps are carefully positioned to form a floodlit path; the light visibly and audibly crackles and hums, while the very last sequence of the film contains images of the two school mistresses accompanying a few girls on a journey outside the walls of the school, travelling in a simple, retro-style train carriage, interior lights flickering on and off. The formal quality of the images themselves also possesses a vibrating, live appeal, rather like electrified atoms or the static energy of lightbulbs; electricity punctuates life within Hadžihalilović’s display cabinet of images, an 'aura' artificially negating their death, or their mortality.

Similarly, light is also artificially present in the office interiors of In My Skin. However, when Esther self-harms for the first time we view everything in darkness. Then, for a few seconds, de Van cuts to images of blue skies framed by mirrored skyscrapers. Thus the 'body' of the film opens itself to light and air, contrasting the confined and claustrophobic office spaces of the rest of the film and its artificial strip lighting. In Trouble Every Day, the blood-red eclipse of morning light and dusky evenings punctuates Denis’s imagery. As Philip Met observes, Agnès Godard's camera 'glides close to the ground, as if over some African savannah, amongst the tall, blood-dripping grasses of a nocturnal open site suffused with tawny tones and amber sodium light where the feline Coré awaits her prey’ (Met 2003).

In Trouble Every Day, In My Skin and Innocence, illumination draws out the material qualities of the film and lends them an uncanny energy that differs from other kinds of 
sensory experience. Just as Denis makes an image of skin, as Nancy argues (Nancy 2008: 6), the images of light in the films discussed here are grafted on to such images of skin, of sensation. In her account of light and its entanglement of touch within the history of metaphysical vision, Cathryn Vasseleu describes how vision, and its historic alignment with knowledge, is rooted in touch, precisely since light is involved in a kind of sensible perception constituted through vision. Most strikingly, this form of light which 'touches the eye’ (Vasseleu 2002) is consuming, painful and ecstatic in a way that precisely resonates with the contexts in which light is found in the sunsets of Trouble Every Day, the lamps and forest sunlight of Innocence and the configuration of air and sky in In My Skin:

(...) When vision is conceived of in terms of an opposition between the intelligible and the sensible, the point at which light contacts the eye is the point where it loses its intelligibility, and becomes associated with the non-rational subjection to feelings such as being penetrated, dazzlement, ecstasy, and pain. (Vasseleu 2002)

This experience of light, above all, comes to represent the sensory potential of the films I have discussed throughout this article; the matter of these films depends on their reflection of light, diegetic light and cinematographic light. Viewers reach a threshold of immersion in the visual through light and its gesture of touch.

\section{Bibliography}

Beugnet, Martine. (2008), ‘Cinema and Sensation: French Film and Cinematic Corporeality’, 
Paragraph, 31:2, pp. 173-188.

Kendall, Tina and Tanya Horeck. (2011), The New Extremism in Cinema: From France to Europe, Edinburgh: Edinburgh University Press.

Met, Philip. (2003), 'Looking for Trouble: The Dialectics of Lack and Excess, Claire Denis’ Trouble Every Day, 3:7 (9 June), http://www.kinoeye.org/03/07/met07.php. Accessed 9 September 2011.

Martin, Adrian. (2009), 'Ticket to Ride: Claire Denis and the Cinema of the Body’, Screening the Past, 20, http://www.latrobe.edu.au/screeningthepast/20/claire-denis.html Accessed 7 August 2011.

Nancy, Jean-Luc. (2008), ‘Icon Fury: Claire Denis’s Trouble Every Day’, Film-Philosophy, 12:1, pp. 1-9. Available online at: http://www.filmphilosophy.com/2008v12n1/nancy.pdf. Accessed 20 September 2011.

Palmer, Tim. (2009), ‘Contemporary French Feminine Cinema and Lucile Hadžihalilović’s Innocence', The French Review 83:2, December 2009, pp. 38-49. (2006), 'Under Your Skin: Marina de Van and the Contemporary French cinéma du corps', Studies in French Cinema, 6:3, pp. 171-181.

Quinlivan, Davina (2009), “'Whispering on the threshold of the flesh”: The Breathing Body, Silence and Embodied Shame in Marina de Van's Dans ma peau (2002)' in J. Chamarette and J. Higgins (eds) Guilt and Shame, Oxford: Peter Lang, pp. 177-188 Romney, J. (2005), 'School for Scandal’, Sight and Sound, 15:10, pp. 34-5.

Sobchack, Vivian. (2005), 'Waking Life: Vivian Sobchack on the Experience of Innocence’, Film Comment, Nov-Dec, pp. 46-9.

Tarr, Carrie. (2006), ‘The Aesthetics of Self-harming in Marina de Van’s Dans ma peau in Gill Rye and Carrie Tarr (eds), ‘Focalizing the Body in Contemporary Women’s Filmmaking in France', Nottingham French Studies, 43:3 (Autumn), pp. 78-91. 
Vasseleu, Cathryn. (2002), ‘Vasseleu’s Reply’, Film-Philosophy,

6:11 http://www.film-philosophy.com/vol6-2002/n11vasseleu. Accessed 12

September 2011.

Wilson, E. (2007), 'Miniature Lives, Intrusion and Innocence: Women Filming Children’, French Cultural Studies, 18:2, pp. 169-183.

\footnotetext{
${ }^{1}$ Hadžihalilović offers these comments in the interview featured as part of the DVD extras for the Artificial Eye release of the film.

${ }^{2}$ Importantly, Romney also cites the influence of Sally Mann's photography, whose portraits of her own children, sometimes naked, were the subject of bitter controversy. Romney's reference to Mann's photography underscores the risks of involving children in aesthetic endeavours, and this issue is explored more fully in Wilson (2007). For Wilson, Hadžihalilović is part of a contemporary group of women filmmakers in France whose work has resisted appropriation of a child's subjective experience.

${ }^{3}$ It may be also useful to see my treatment of Innocence's visual style and, in particular, its evocation of sound and movement as a form of filmic kinaesthesia. Quinlivan, 'Material Hauntings: The Kinaethesia of Sound in Innocence (Hadžihalilović, 2004)', Studies in French Cinema 9(3): 215-224

${ }^{4}$ I refer here to the use of the term adopted by Wilson in her essay 'Miniature Lives, Intrusion and Innocence'; Innocence is a work which aesthetically and politically troubles boundaries, makes incisions and crucially uses cinematic art to think through, and make palpable, questions of intrusion and intimacy' (2007: 170).

${ }^{5}$ A more detailed reflection on the subject of the breathing body in In My Skin can be found in my article Quinlivan (2009).
} 